\title{
Meiosis in Radiation Induced Triploid and Tetraploid Plants of Pearl Millet
}

\author{
R. B. Singh, B. D. Singh, R. M. Singh and Vijai Laxmi \\ Department of Genetics and Plant Breeding, Banaras Hindu University, \\ Varanasi 221005, India
}

Received March 16, 1976

Tetraploid and triploid plants have been induced in pearl millet, and during meiosis show univalents, trivalents, quadrivalents and even higher associations (Krishnaswami and Rangaswami Ayyanger 1941, Gill et al. 1969, 1970, Jauhar 1970). In tetraploid the frequency of multivalents decreases with a concomitant increase in the number of bivalents in subsequent generations (Gill et al. 1969, Jauhar 1970). In triploids univalents, bivalents and trivalents (Pontulu 1968), and even quadrivalents (Gill et al. 1970), have been observed.

In the present paper we report regular bivalent formation during meiosis in a tetraploid pearl millet and the meiotic behaviour of a triploid pearl millet, both induced by gamma-rays.

\section{Materials and methods}

Dry seeds of seven elite inbreds, viz., Tif $23 \mathrm{~A}, 23 \mathrm{D}_{2} \mathrm{~A}$ (male sterile lines); Tif 23B, $23 \mathrm{D}_{2} \mathrm{~B}$ (maintainers); K560, Bi13B and $\mathrm{J} 104$ (restorers), and of three hybrids, viz., HB1 (Tif 23A $\times$ Bi13B), HB3 (Tif 23A $\times$ J104) and HB5 (Tif 23A $\times$ K559), were irradiated with 10, 20 and $30 \mathrm{kr}$ gamma-rays, treated with 0.2, 0.4 and $0.6 \%$ EMS (Ethylmethane sulfonate) and with the nine possible combinations of $\gamma$-rays and EMS (Singh et al. 1976). The treated material was grown in field alongwith the controls.

PMCs were fixed in the modified Carnoy solution ( 1 acetic acid: 3 chloroform: 6 ethyl alcohol) to which ferric acetate was added ( 2 drops of saturated aqueous solution per $100 \mathrm{ml}$ fixative). Squashes were prepared in $2 \%$ acetocarmine.

\section{Results and discussion}

Out of 996 plants analysed cytologically, one plant was triploid ( $3 n)$ and another tetraploid (4n). The triploid plant occurred in the population of HB3 treated with $20 \mathrm{kr}$ gamma-rays $+0.2 \%$ EMS, while the tetraploid plant was isolated from $20 \mathrm{kr}$ gamma-ray irradiated population of HB1. It is significant to note that both the polyploids were obtained from hybrids.

The triploid showed univalents and trivalents in all the cells both at diakinesis and metaphase I (MI). The number of trivalent associations ranged from 1 to 6 per cell, while that of univalents ranged from 1 to 9 per cell (Figs. 1-3). The orien- 
tation of chromosomes at metaphase plate was normal. At anaphase I (AI), 32.2\% of the cells exhibited 10:11 chromosome distribution, $25.8 \%$ showed 13: 8 (Fig. 4), and $19.3 \%$ had 9:12 separation. Lagging chromosomes, one (16.1\%) or two $(6.5 \%)$ per cell, were also observed (Fig. 5). In some of the cases, the laggards failed to be included in either of the dyad. Average pollen sterility was $40 \%$. Meiosis in triploid pearl millet induced spontaneously (Krishnaswamy and Rangaswami Ayyanger 1941), by gamma-irradiation (Pontulu 1968) or obtained from colchicine induced tetraploids (Gill et al. 1970, Narendra 1973) has been studied. Krishnaswamy and Rangaswamy Ayyanger (1941) and Gill et al. (1970) observed univalents, bivalents and multivalents, while Pontulu (1968) and Narendra (1973) observed no associations higher than trivalent. The findings of the present study agree with those of Pontulu (1968) and Narendra (1973). It should be noted that the triploid of the present study and that of Pontulu were induced by gamma-rays.

Table 1. Chromosomal associations at diakinesis and metaphase I in a triploid pearl millet plant

\begin{tabular}{lcc}
\hline \multirow{2}{*}{ Configuration } & \multicolumn{2}{c}{ Per cent of cells } \\
\cline { 2 - 3 } & Diakinesis & Metaphase I \\
\hline $6^{\mathrm{III}}+1^{\mathrm{II}}+1^{\mathrm{I}}$ & 8.9 & 4.5 \\
$5^{\mathrm{III}}+2^{\mathrm{II}}+2^{\mathrm{I}}$ & 5.3 & 4.5 \\
$5^{\mathrm{III}}+1^{\mathrm{II}}+4^{\mathrm{I}}$ & 7.1 & 7.6 \\
$4^{\mathrm{II}}+2^{\mathrm{II}}+5^{\mathrm{I}}$ & 12.5 & 10.6 \\
$4^{\mathrm{III}}+4^{\mathrm{II}}+1^{\mathrm{I}}$ & 8.9 & 9.1 \\
$4^{\mathrm{II}}+3^{\mathrm{II}}+3^{\mathrm{I}}$ & 7.1 & 12.1 \\
$3^{\mathrm{III}}+5^{\mathrm{II}}+2^{\mathrm{I}}$ & 12.5 & 12.1 \\
$3^{\mathrm{III}}+4^{\mathrm{II}}+4^{\mathrm{I}}$ & 14.2 & 10.6 \\
$3^{\mathrm{III}}+2^{\mathrm{II}}+8^{\mathrm{I}}$ & 7.1 & 9.1 \\
$2^{\mathrm{III}}+3^{\mathrm{II}}+9^{\mathrm{I}}$ & 8.9 & 10.6 \\
$1^{\mathrm{III}}+6^{\mathrm{II}}+6^{\mathrm{I}}$ & 7.1 & 9.1 \\
\hline Number of cells analysed & 56 & 66 \\
\hline
\end{tabular}

The tetraploid plant had thicker stem, larger leaves, longer head and profuse basal as well as nodal tillering as compared to the normal diploid. This plant was chimeral; two of the three tillers tested were tetraploid. It flowered 11 days earlier than the diploids, showed high pollen sterility $(98.7 \%$ ) and very poor seed set.

The tetraploid showed an interesting meiotic behaviour. At MI only bivalents were observed; 2 to 12 bivalents showed secondary associations (Figs. 6, 7) in 78.1 per cent of the cells. At AI, chromosome separation was regularly 14: 14 (Fig. 8); most of the separating chromosomes also showed associations of two homologues as if the disjunction was bivalent vs. bivalent. The secondary association between the "homologous" bivalents, thus, profoundly affected the behaviour of chromosomes at AI and at AII (Fig. 8). At AI, 7 bivalents, not 14 chromosomes, moved to each of the two poles and at AII, 7 chromosomes, not 14 chromatids, moved to each of the poles. Thus each nucleus of the tetrad received 7 chromosomes, which are equivalent to 14 chromatids. Sometimes, chromosomes rather than bivalents separated at AI. The behaviour of such chromosomes at AII is not clear; an uneven 

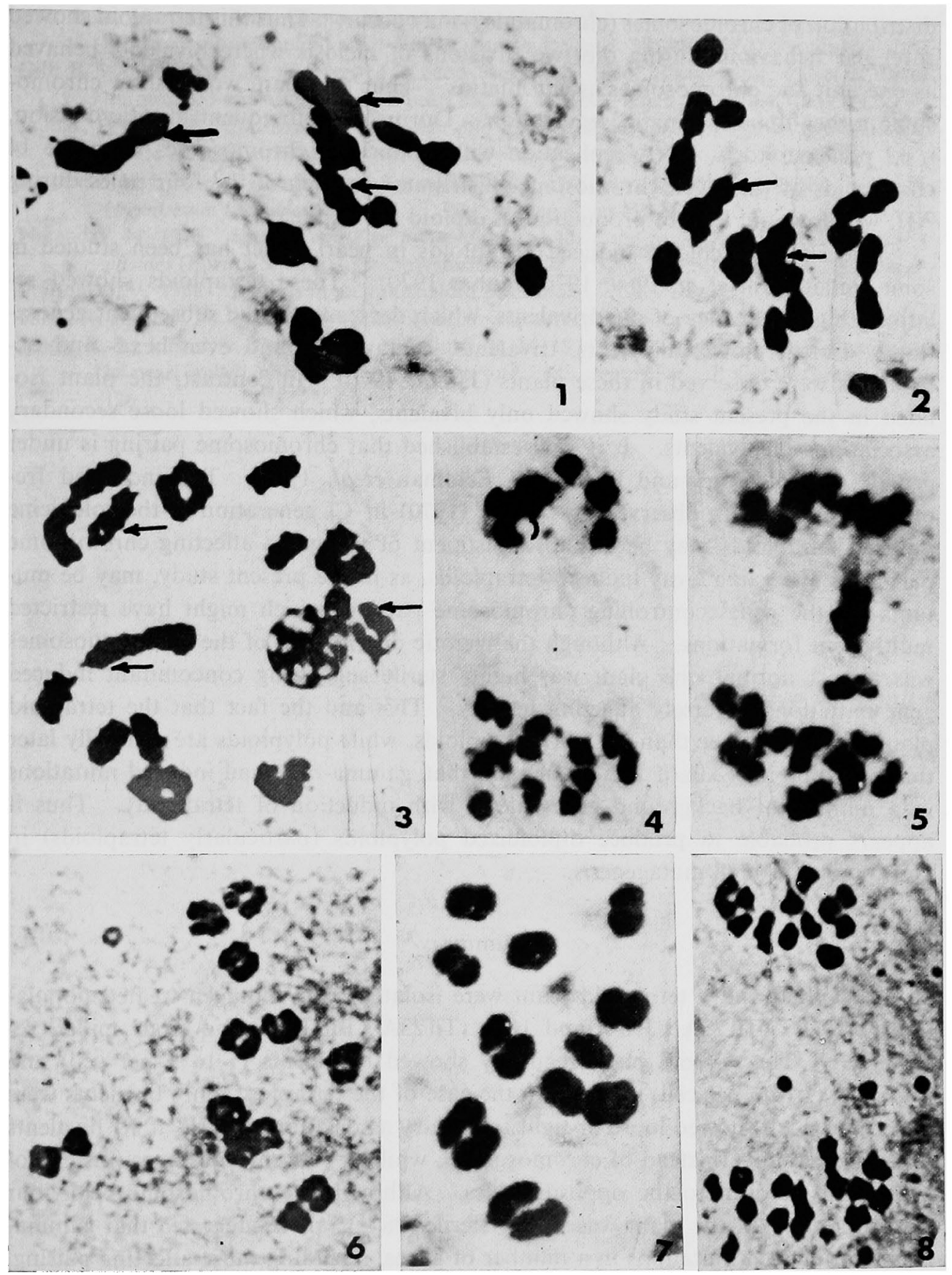

Figs. 1-8, 1-5. Meiosis in gamma-ray induced triploid pearl millet. 1, MI with $3^{\text {III }}$ (arrows) $+5^{\text {II }}+2^{\text {I }}$. 2, MI with $2^{\text {III }}$ (arrows) $+4^{\text {II }}+7^{\text {I }} . \quad 3$, diakinesis with $3^{\text {III }}$ (arrows) $+4^{\text {II }}+4^{\text {I }} .4$, AI showing 13: 8 separation. 5, AI with lagging chromosomes. 6-8. Meiosis in gamma-ray induced tetraploid pearl millet. 6 , MI with $14^{\text {II }}$. Ten bivalents show secondary association. 7, MI with 14II. Eight bivalents show secondary association. 8, early $\mathrm{A}_{\mathrm{II}}$ showing separation of chromosomes. 
distribution of chromosomes (chromatids?) may occur. Thus this tetraploid showed a regular behaviour during the two divisions of meiosis where bivalents behaved as one unit and chromosomes as chromatids. Thus this plant would show chromosome rather than chromatid segregation. During the subsequent mitotic division, i. e., pollen mitosis, DNA replication will produce 14 chromosomes from the 14 chromatids of the seven chromosomes distributed to each of the four poles during AII, which would lead to production of diploid $(2 n)$ gametes.

Meiosis of colchicine induced tetraploids in pearl millet has been studied in some detail (Gill et al. 1969, 1970, Jauhar 1970). These tetraploids showed relatively high frequency of quadrivalents, which decreased in the subsequent generations. Furthermore, univalents, trivalents, pentavalents and even hexa- and octavalents were observed in these plants (Jauhar 1970). In contrast, the plant isolated in the present study showed only bivalents, which showed loose secondary associations of bivalents. It is well established that chromosome pairing is under genetic control (Riley and Law 1965, Feldman et al. 1966). The increased frequency of bivalents observed by Jauhar (1970) in $\mathrm{C}_{6}$ generation of the colchicine induced tetraploids may be due to adjustment of the genes affecting chromosome pairing. The gamma-ray induced tetraploids, as in the present study, may be mutants for the genes controlling chromosome pairing, which might have restricted multivalent formations. Although the meiotic distribution of the $4 n$ chromosomes was almost normal, the plant was highly sterile suggesting concomitant induced gene mutations adversely affecting fertility. This and the fact that the tetraploid plant flowered earlier than the normal diploids, while polyploids are generally later than the diploids (Allard 1960), suggests that gamma-rays had induced mutations in a number of background genes along with induction of tetraploidy. Thus it appears probable to produce diploidized polyploids (particularly tetraploids) in crop plants through mutagenesis.

\section{Summary}

A triploid and a tetraploid plant were isolated from mutagen treated populations of HB3 (Tif $23 \mathrm{~A} \times \mathrm{J} 104$ ) and HB1 (Tif $23 \mathrm{~A} \times \mathrm{Bil3B}$ ) hybrid pearl millet, respectively. The triploid plant regularly showed univalents ( 1 to 9 per cell) and trivalents ( 1 to 6 per cell) at MI. In the case of the tetraploid, only bivalents were observed which showed loose or tight secondary associations at MI; at AI bivalents separated as units (instead of chromosomes), while at AII chromosomes (instead of chromatids) moved to the opposite poles. Although the chromosome behaviour was quite regular, the plant was highly sterile $(98 \%)$. It is suggested that gammarays had induced mutations in a number of genes, including those affecting pairing, concomitant to the indution of tetraploidy.

\section{References}

Allard, R. W. 1960. Principles of Plant Breeding, pp. 370-376, John Willey and Sons, New York. Feldman, M., Mello-Sampayo, T. and Sears, E. R. 1966. Somatic association in Triticum aestivum. Proc. Nat. Acad. Sci. (U.S.) 56: 1192-1199. 
Gill, B. S., Minocha, J. L., Gupta, D. and Kumar, D. 1969. Chromosome behaviour and seed setting in autotetraploid pearl millet. Indian J. Genet. 29: 462-467.

Gil, B. S., Minocha, J. L., George, M. K. and Brar, D. S. 1970. Cytological studies in diploid, autotriploid and autotetraploid pearl millet. J. Res. Punjab Agr. Univ. 7: 417-422,

Jauhar, P. P. 1970. Chromosome behaviour and fertility of the raw and evolved synthetic tetraploids of pearl millet Pennisetum typhoides Stapf et Hubb. Genetica 41: 407-424.

Krishnaswamy, N. and Rangaswami Ayyangar, G. N. 1941. An autotriploid in the pearl millet (Pennisetum typhoides S. and H.). Proc. Indian Acad. Sci. 138: 9-23.

Narendra, N. 1973. Establishment of aneuploids and their use in pearl millet (Pennisetum typhoides (Burm.) S. and H.) improvement. Ph.D. Thesis, Meerut University, Meerut.

Pontulu, J. V. 1968. Meiosis in an autotriploid pearl millet. Caryologia 21: 11-15.

Riley, R. and Law, C. N. 1965. Variation in chromosome pairing. Advances Genet. 13: 57-114.

Singh, R. B., Laxmi, V., Singh, B. D. and Singh, R. M. 1976. Induction of resistance to diseases in pearl millet inbreds by gamma-rays and EMS treatments. J. Cytol. Genet. 2: 122126. 